\title{
Analisis Metode Pengenalan Wajah Two Dimensial Principal Component Analysis (2DPCA) dan Kernel Fisher Discriminant Analysis Menggunakan Klasifikasi KNN (K- Nearest Neighbor)
}

\author{
Abdur Rohman Harits Martawireja ${ }^{1}$, Hilman Mujahid Purnama ${ }^{2}$, Atika Nur Rahmawati ${ }^{3}$ \\ 1,2,3 Jurusan Otomasi Manufaktur dan Mekatronika, Politeknik Manufaktur Bandung
}

Email: harits@polman-bandung.ac.id

\begin{tabular}{|c|c|}
\hline Informasi Artikel: & ABSTRAK \\
\hline $\begin{array}{l}\text { Received: } \\
11 \text { Mei } 2020 \\
\\
\text { Accepted: } \\
25 \text { September } 2020 \\
\\
\text { Available: } \\
15 \text { Oktober } 2020\end{array}$ & $\begin{array}{l}\text { Pengenalan wajah manusia (face recognition) merupakan salah satu } \\
\text { bidang penelitian yang penting dan belakangan ini banyak aplikasi yang } \\
\text { menerapkannya, baik di bidang komersil ataupun di bidang penegakan } \\
\text { hukum. Pengenalan wajah merupakan sebuah sistem yang berfungsikan } \\
\text { untuk mengidentifikasi berdasarkan ciri-ciri dari wajah seseorang } \\
\text { berbasis biometrik yang memiliki keakuratan tinggi. Pengenalan wajah } \\
\text { dapat diterapkan pada sistem keamanan. Banyak metode yang dapat } \\
\text { digunakan dalam aplikasi pengenalan wajah untuk keamanan sistem, } \\
\text { namun pada artikel ini akan membahas tentang dua metode yaitu Two } \\
\text { Dimensial Principal Component Analysis dan Kerne/ Fisher Discriminant } \\
\text { Analysis dengan metode klasifikasi menggunakan K-Nearest Neigbor. } \\
\text { Kedua metode ini diuji menggunakan metode cross validation. Hasil dari } \\
\text { penelitian terdahulu terbukti bahwa sistem pengenalan wajah metode } \\
\text { Two Dimensial Principal Component Analysis dengan 5-folds cross } \\
\text { validation menghasilkan akurasi sebesar } 88,73 \% \text {, sedangkan dengan } 2- \\
\text { folds validation akurasi yang dihasilkan sebesar } 89,25 \% \text {. Dan pengujian } \\
\text { metode Kernel Fisher Discriminant dengan 2-folds cross validation } \\
\text { menghasilkan akurasi rata rata sebesar } 83,10 \% \text {. }\end{array}$ \\
\hline
\end{tabular}

\section{Kata Kunci:}

Pengenalan Wajah, 2DPCA,

Kernel Fisher

Discriminant

Analysis,

$K K N$

\begin{abstract}
Face recognition is one of the most importants research fields and lately many applications apply it, both in the commercial and law enforcement fields. Face recognition is a system that used to identify based on the facial characteristic of a biometric-based person which has high accuracy. Face Recognition can be used in security system. Many methods are used in face recognition for security system, but in this paper will discuss only about 2 methods, there are Two Dimensial Principal Component Analysis and Kernel Fisher's Discriminant Analysis and each methods use $K$-Nearest Neighbor for the class classification. For the testing system, both of them use the cross validation testing method. From the previous research, the face recognition accuracy with 5-folds cross validation of Two Dimensial Principal Component Analysis method is $88,73 \%$, while the accuracy with 2-folds cross validation of it is $89,25 \%$. And the average of Kernel Fisher Discriminant Analysis' accuracy is about $83,10 \%$.
\end{abstract}




\section{PENDAhUlUAN}

Perkembangan industri 4.0 mengakibatkan perkembangan di bidang teknologi komputer sekarang sangat pesat, hal ini ditandai dengan hampir semua pengolahan data dan informasi dilakukan dengan menggunakan komputer. Semakin banyak permasalahan yang bisa di tangani dengan computer tidak menutup kemungkinan juga semakin banyak timbul permasalahan informasi yang harus ditangani, salah satu nya adalah dalam hal keamanan sistem dan jaringan. Sistem kemananan yang banyak digunakan dalam dunia usaha adalah pengenalan wajah. Banyak aplikasi teknologi pengenalan wajah telah di terapkan pada proses dan sistem yang membutuhkan, diantaranya adalah pada sistem absensi, verifikasi daftar penjahat di kepolisisan, pemrosesan Visa, dan verifikasi Paspor [1].

Dengan input citra wajah manusia, sebuah algoritma pengenalan wajah menghasilkan informasi identitas individu seperti nama, jenis kelamin, pekerjaan dan masih banyak lagi. Pembuatan algoritma pengenalan wajah memiliki beberapa tantangan diantaranya bentuk struktur wajah yang sama, yakni oval ataupun bulat. Faktor perbedaan lain yang cukup menentukan dari suatu citra wajah pada orang yang samayaitu perubahan gaya rambut maupun adanya aksesories pada wajah mereka, seperti menggunakan kacamata atau topi. Faktor tantangan lain yang dapat mempengaruhi pengenalan wajah yaitu rendahnya kualitas kamera dan noise pada saat pengambilan citra [2].

Dalam pengenalan wajah terdapat metode yang digunakan pada penelitian ini, yaitu Two Dimensial Principal Component Analysis (2DPCA). Akhir-akhir ini, pendekatan analisis komponen utama dua dimensi (2DPCA) telah diusulkan untuk representasi dan pengenalan wajah dengan senyuman [3]. Sementara itu Kernel Fisher's Discriminant Analysis And Nearest Neighbor (KNN), Artikel ini dilakukan dengan tujuan untuk mengetahui metode yang lebih akurat.

\section{PENELITIAN TERKAIT}

Pada penelitian terdahulu, metode Two Dimensial Principal Component Analysis (2DPCA), dan Kernel Fisher's Discriminant Analysis And Nearest Neighbor telah banyak digunakan untuk mengembangkan aplikasi keamanan biometric diberbagai sektor, maupun penelitian terhadap metode itu sendiri.

\subsection{Metode Two Dimensial Principal Component Analysis (2DPCA)}

Principal Component Analysis (PCA), juga dikenal sebagai Karhunen-Ekspansi loeve, merupakan ekstraksi fitur dan teknik representasi data klasik yang digunakan di bidang pola pengenalan dan visi komputer [4]. Sirovich dan Kirby [5], pertama menggunakan PCA untuk merepresentasikan gambar wajah manusia secara efisien. Pada Penelitian E.B.Utomo [1], pengenalan wajah dilakukan dengan cakupan atau parameter yang lebih sempit, dengan bentuk ekspresi yang berbeda-beda dan wajah yang dikelilingi oleh kain kerudung menjadikan sistem pengenalan wajah semakin kompleks dalam memproses hasil dari pengambilan foto.

Esensi dari 2DPCA adalah menghitung vector eigen atau yang disebut matrik kovarian tanpa mengkonversi matrik citra ke bentuk vektor sehingga ukurannya lebih kecil, lebih mudah mengevaluasi kovarian matriknya, komputasinya berkurang dan unjuk kerjanya juga meningkat [3]. Proses pengenalan wajah representasi gambar dan ekstraksi fitur merupakan teknik yang umum digunakan dalam pengenalan wajah. Pada PCA matriks dari suatu gambar 
Analisa Metode Pengenalan Wajah Two Dimensial Principal Component Analysis (2DPCA) dan Kernel Fisher Discriminant Analysis Menggunakan Metode Klasifikasi KNN ( $K$-Nearest Neighbor)

diubah menjadi matriks vektor berdimensi tinggi, yang bermanfaat untuk menghitung matriks kovarians ruang vektor dimensi tinggi. Namun kendala utama yang terjadi adalah bahwa matriks kovarians menjadi ukuran yang besar, dimana akan mengakibatkan sejumlah besar pelatihan dengan sampel kecil akan sulit dalam melakukan evaluasi secara akurat. Selain itu dibutuhkan banyak waktu untuk menghitung vektor eigen berikutnya. Untuk mengatasi ini kesulitan Two- Dimensional Principal Component Analysis (2DPCA) memberikan cara untuk menangani keterbatasan ini [6]. Metode 2DPCA dapat didefinisikan sebagai berikut, Jika $A$ merupakan matriks citra asli berukuran $m \times n$ dan $X$ merupakan matriks dengan kolom orthonormal, maka 2DPCA merupakan proyeksi $A$ pada $X$ dengan persamaan [7] [8]:

$$
\boldsymbol{Y}=\boldsymbol{A X}
$$

Cara menentukan matriks $X$ optimal untuk proyeksi citra adalah sebagai berikut . Terdapat persamaan :

$$
J(\boldsymbol{X})=\operatorname{tr}(\boldsymbol{S} x)
$$

$S x$ merupakan matriks kovariansi dari proyeksi vektor fitur dari data training, Secara matematis $S x$ didefinisikan sebagai :

$$
S x=E(\boldsymbol{Y}-E \boldsymbol{Y})(Y-E \boldsymbol{Y})^{T}
$$

Memasukkan persamaan 1.1 kedalam persamaan 1.3, sehingga di dapat :

$$
\begin{gathered}
\boldsymbol{S} x=E[\boldsymbol{A} \boldsymbol{X}-E(\boldsymbol{A} \boldsymbol{X})][\boldsymbol{A} \boldsymbol{X}-E(\boldsymbol{A} \boldsymbol{X})]^{T} \\
\boldsymbol{S} x=E[\boldsymbol{A}-E \boldsymbol{A}) X][(\boldsymbol{A}-E \boldsymbol{A}) \boldsymbol{X}]^{T} \\
\operatorname{tr}(\boldsymbol{S} x)=\boldsymbol{X}^{T}\left[E(\boldsymbol{A}-E \boldsymbol{A})^{T}(\boldsymbol{A}-E \boldsymbol{A})\right] X
\end{gathered}
$$

Maka dari persamaan (1.6) dibuat menjadi :

$$
J(\boldsymbol{X})=X^{T}\left[(\boldsymbol{A}-E(\boldsymbol{A}))^{T}(\mathrm{~A}-\mathrm{E}(\mathbf{A}))\right] \mathrm{X}
$$

Berikutnya dimisalkan $G$ yaitu matriks kovariansi citra definit non negative berukuran $n \times n$ sebagai berikut :

$$
\boldsymbol{G} t=E\left[(\boldsymbol{A}-E \boldsymbol{A})^{T}(\mathbf{A}-\mathrm{EA})\right]
$$

Maka persamaan (1.6) dapat diubah menjadi :

$$
J(X)=\boldsymbol{X}^{T} \boldsymbol{G} t \boldsymbol{X}
$$

Misalkan M menunjukkan jumlah total sampel dari citra latih, citra latih ke-k dilambangkan dengan matriks $\mathrm{m} \times \mathrm{n}$ Ak $(\mathrm{k}=1,2,3 \ldots \mathrm{M})$ dan rata-rata dari semua sampel training dilambangkan dengan $\overline{\boldsymbol{A}}$, Maka Maka $G$ dapat dihitung sebagai [8] :

$$
\left.\mathrm{Gt}=\frac{1}{M} \sum_{k=1}^{M}\left(\boldsymbol{A}_{k}-\overline{\boldsymbol{A}}\right)\right)^{T}\left(\boldsymbol{A}_{k}-\overline{\boldsymbol{A}}\right)
$$


K-Nearest Neigbor KNN adalah algoritma mudah yang menyimpan semua kasus yang tersedia dan mengklasifikasikan kasus baru berdasarkan kesamaan pengukuran. Algoritma K-Nearest Neighbor (K-NN) adalah sebuah metode klasifikasi terhadap sekumpulan data berdasarkan pembelajaran data yang sudah terklasifikasikan sebelumya. Termasuk dalam supervised learning, dimana hasil query instance yang baru diklasifikasikan berdasarkan mayoritas kedekatan jarak dari kategori yang ada dalam KNN [9]. Gambar 1 Merupakan gambaran konsep kedekatan data pada KKN.

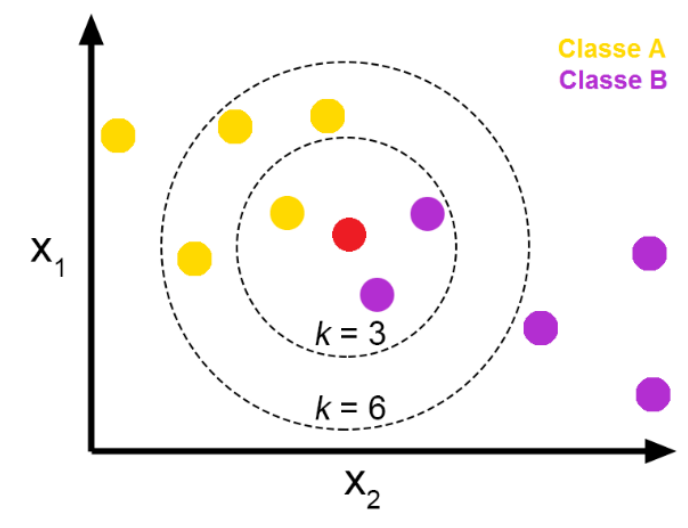

Gambar 1. Gambaran Konsep KKN

Tahapan Langkah Algoritma KNN antara lain Menentukan parameter k (jumlah tetangga paling dekat), Menghitung kuadrat jarak eucliden objek terhadap data training yang diberikan, Mengurutkan hasil no 2 secara ascending (berurutan dari nilai tinggi ke rendah), Mengumpulkan kategori Y (Klasifikasi nearest neighbor berdasarkan nilai k), Dengan menggunakan kategori nearest neighbor yang paling mayoritas maka dapat dipredisikan kategori objek. Jarak Euclidean antara sampel uji dan semua sampel pelatihan dihitung. Jarak Euclidean dalam KKN diberikan oleh Persamaan [10]:

$$
d=\sqrt{\sum_{i=1}^{n}\left(x_{i}-y_{1}\right)^{2}}
$$

dimana $d(m, n)$ adalah jarak antara dua pola $m$ dan $n . v$ menunjukkan nilai fitur ke-v. $p$ adalah jumlah fitur. Nilai jarak terkecil tidak lain adalah sampel latih yang paling dekat dengan sampel uji. Jadi sampel uji diklasifikasikan menurut tetangga terdekat.

Dalam pengumpulan data pada penelitian yang dilakukan Utomo $\mathrm{E} B[1]$ dengan cara menjumpai dan mengambil gambar (foto) secara langsung wajah wanita yang berkerudung. Dan pada penelitian ini setelah pengambilan data, tahapan selanjutnya proses indentifikasi wajah yang diharuskan melalui tahapan-tahapan Pre-processing merupakan proses konversi citra dari RGB menuju grayscale. Selanjutnya Proses Ekstraksi 2DPCA Citra wajah yang digambarkan dalam matriks kemudian akan ditransformasikan, dan menghasilkan proyeksi vektor agar dapat diproses pada tahapan pengenalan. Proses Pengenalan KNN (Euclidian Distance) Proses klasifikasi $K$-Nearest Neigbor (KNN) ini menggunakan metode Euclidian distance. Matriks citra wajah yang diperoleh dari transformasi dengan menggunakan 2DPCA, dimana training dataset yang diekstraksi menghasilkan eigenvector yang digunakan untuk mendapatkan eigenface. 
Analisa Metode Pengenalan Wajah Two Dimensial Principal Component Analysis (2DPCA) dan Kernel Fisher Discriminant Analysis Menggunakan Metode Klasifikasi KNN ( $K$-Nearest Neighbor)

Metode $K$-Fold Cross Validation selanjutnya akan digunakan untuk mengevaluasi metodemetode yang telah diterapkan. Metode ini dipilih karena tidak membutuhkan waktu yang banyak dalam membuat variasi data uji dalam pengujian dan lebih mudah. K-Fold Cross Validation digunakan dalam pembelajaran pada data training untuk menentukan keakuratan suatu algoritma sehingga dapat menguji data testing. Pada setiap fold akan diuji dan dihitung hasil akurasinya, dan kemudian dihitung rata-rata seluruh akurasi untuk mendapatkan hasil akurasi secara keseluruhan. Tingkat akurasi dapat dihitung dengan rumus :

$$
\text { Tingkat Akurasi }=\frac{\Sigma \text { data uji benar diklasifikasi }}{\Sigma \text { total data uji }} \times 100 \%
$$

Pengujian pada penelitian utomo E B [1] didasari pada pengumpulan data, Serta pengujian didasari dari variasi data, yakni wajah wanita sebanyak 40 orang setiap orang diambil 10 foto dengan ekspresi wajah berbeda seperti Gambar 2. dan wajah wanita berkerudung yang sebelumnya diambil langsung sebanyak 7 orang, dimana setiap orang diambil 10 foto dengan 2 model kerudung pada setiap orangnya seperti pada Gambar 2.
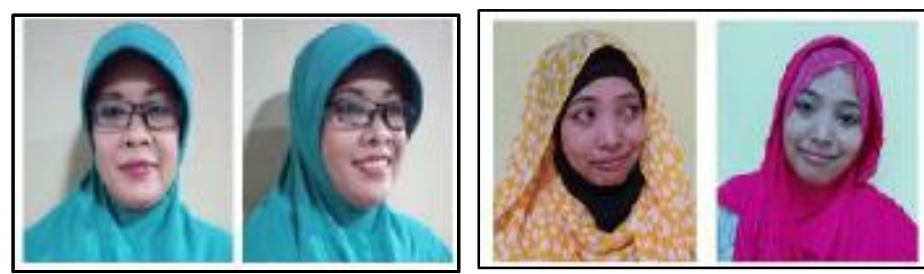

Gambar 1. Wajah Wanita Berkerudung 1 Model dan 2 Model [1].

\subsection{Kernel Fisher's Discriminant Analysis}

Pada penelitian I.Setyawan Et all [11], dilakukan implementasi dari KFDA dan algoritma KNN untuk membuat sistem face recognition. Kombinasi KFDA dan algoritma KNN ini dapat mengklasifikasikan seseorang menjadi 2 kelas, yaitu kelas suspect dan kelas non-suspect. KFDA pada sistem digunakan sebagai fitur ekstraksi, sedangkan algoritma KNN digunakan sebagai pengklasifikasi kelas. Metode Kernel Fisher's Discriminant Analysis atau dapat disingkat KFDA, merupakan hasil dari pengembangan metode Liniear Discriminant Analysis (LDA). LDA digunakan untuk memisahan data antara 2 kelas yang berbeda dan meminimalisir jarak antara data yang berada di kelas yang sama. Kombinasi LDA dan fungsi kernel ini menyebabkan transformasi linier.

Keuntungan hasil pengembangan ini yaitu KFDA dapat mengolah atau memproses banyak data dengan dimensi vektor yang besar. Data dengan dimensi besar ini akan menjadi proyeksi vektor yang baru. Untuk menerapkan fungsi non-linear kernel ini, dibutuhkan transformasi vektor original menjadi Hilbert Space $F$ melalui pemetaan non-linear fungsi $\varnothing$. Berikut prosedur metode KFDA [11] :

1. Memasukkan matriks $K$ dan $W$

K merupakan matriks kernel yang digunakan dalam metode KFDA. $N$ merupakan banyak nya kelals. $P$ dan $q$ adalah kelas kelas yang tersedia.

$$
\mathrm{K}=\underset{\mathrm{q}=2, \ldots, \mathrm{N}}{\left(\mathrm{K}_{\mathrm{pq}}\right)_{\mathrm{p}=1, \ldots, \mathrm{N}}}
$$


Matriks $W$ adalah matriks block diagonal. Pada setiap $W_{1}$ adalah matriks $M \times M$ yang semua elemen nya setara dengan $1 / M$, dan $M$ adalah banyaknya sampel training dikelas l.

$$
W=\left(W_{1}\right)_{\mid=1, \ldots, N}
$$

2. Memasukkan $K$ menggunakan dekomposisi eigenvectors

$$
\mathrm{K}=\mathrm{P} \Gamma^{-1} \mathrm{P}
$$

$\Gamma$ adalah matriks yang berisi eigenvalues dari $K$. $P$ pada persamaan diatas adalah matriks orthonormal seperti $P^{T} P=I$, dimana $I$ adalah matriks identitas.

3. Memasukkan eigenvector $\beta$ dan eigenvalues $\lambda$ dari sistem

$$
\Lambda \beta=P^{\top} W P \beta
$$

4. Memasukkan eigenvector $v$ menggunakan $a$

$$
\begin{aligned}
& a=P \Gamma^{-1} \beta \\
& v^{\top} v=a^{\top} K a=I
\end{aligned}
$$

5. Memasukkan proyeksi dari titik uji $z$ ke eigenvectors $v$

$$
\mathrm{v}^{\top} \varnothing(\mathrm{z})=\sum_{p=1}^{N} \sum_{q=1}^{n p} \alpha_{\mathrm{pq}} \mathrm{K}\left(\mathrm{x}_{\mathrm{pq}}, \mathrm{z}\right)
$$

Proses pengklasifikasian kelas menggunakan algoritma $K$-Nearest Neighbor (KNN). KKN digunakan untuk mengukur jarak dari titik yang dicari terhadap titik data training. Perhitungan ini juga menggunakan kriteria Euclidian distance guna mencari jarak antar vektor. Dalam perhitungan ini, vektor $p$ dan $q$ merupakan hasil vektor dari proses ekstrasi KFDA. Dan Panjang dari vektor, $n$, adalah parameter yang akan kita tentukan. Dengan algoritma ini maka dipilih dari KNN vektor uji untuk menentukan kelas mana yang cocok.

Anggap $p=\left(p_{1}, p_{2}, \ldots, p_{n}\right)$ dan $q=\left(q_{1}, q_{2}, \ldots, q_{n}\right)$, maka persamaan Euclidian distance nya adalah :

$$
\text { Euclidian distance }=\sqrt{\sum_{i=1}^{n}\left(p_{i}-q_{i}\right)^{2}}
$$

Berikut konsep implementasi untuk percobaan sistem face recognition, pertama membuat dataset gambar/foto wajah dengan variasi pose, ekpresi wajah dan aksesoris, lalu membuat data training vektor dan data uji vektor dari gambar, setelahnya ada proses data vektor enggunakan KFDA dan klasifikasikan menggunakan kriteria KNN, terakhir menghitung keberhasilan metode KFDA-NN menggunakan cross validation.

\section{ANALISIS SISTEM}

Analisa sistem ini berisi hasil penelitian pengenalan wajah dengan 2 metode, Two Dimensial Principal Component Analysis (2DPCA) dan metode Kernel Fisher's Discriminant Analysis . 
Analisa Metode Pengenalan Wajah Two Dimensial Principal Component Analysis (2DPCA) dan Kernel Fisher Discriminant Analysis Menggunakan Metode Klasifikasi KNN ( $K$-Nearest Neighbor)

Dua penelitian ini menggunakan metode KNN dalam mengklasifikasikan hasil ekstraksi foto atau gambar.

\subsection{Metode Two Dimensial Principal Component Analysis (2DPCA)}

Dalam pengujian pada penelitian ini dilakukan dengan empat tahap, berikut hasil dari pengujian pada penelitian dengan menggunakan metode Two Dimensial Principal Component Analysis (2DPCA).

Pengujian pertama pada penelitian Utomo E B [1], dengan data training wajah wanita 1 model kerudung dengan jumlah 40 sampai 360 orang, menggunakan semua eigenvector hasil ekstraksi. Didapat hasil uji dihasilkan 95\% dengan waktu proses 13,2485 detik. Pengujian kedua, menggunakan data training wajah 1 wanita berkerudung jumlah 40 sampai 360 dengan menggunakan beberapa eigenvector hasil ekstraksi. Didapat nilai akurasi paling tinggi 97,5\% dengan penggunaan 2 nilai eigen dengan waktu proses 13,4942 detik, penggunaan nilai eigen 4 dan 5 dengan waktu proses 14,123 detik dan 14,2723 detik.

Pengujian ketiga, menggunakan data training wajah wanita 2 model berkerudung dengan jumlah 42 sampai 63 dengan menggunakan semua eigenvector hasil ekstraksi. Didapat dilai akurasi $14,28 \%$ data training dengan waktu rata-rata 1,225 detik. Pengujian keempat, menggunakan data training wajah wanita 2 model berkerudung dengan jumlah 42 sampai 63 dengan menggunakan beberapa eigenvector hasil ekstraksi. Dimana pada pengujian 63 data training dihasilkan akurasi paling tinggi 14,2857 \% dengan penggunaan 3 nilai eigen didapat waktu proses 1,3064 detik lebih cepat dibandingkan dengan penggunaan nilai eigen 4 dan 5 dengan waktu proses 1,3515 detik dan 1,3551 detik.

Dengan empat hasil pengujian pada sistem ini, didapat bahwa semakin banyak jumlah data training yang digunakan maka tingkat akurasi yang dihasilkan semakin tinggi. ketika pengujian menggunakan banyak jumlah eigenvector maka waktu proses akan semakin lama. Tabel 1 merupakan hasil validasi akurasi dataset dengan menggunakan $K$-Fold Cross Validation pada 10 data citra wajah.

Tabel 1. Hasil Pengujian Dengan K-Fold Cross Validation dari Penelitian Utomo E.B.

\begin{tabular}{|c|c|c|c|c|c|c|}
\hline $\begin{array}{c}\text { Jumlah } \\
\text { Eigenvector }\end{array}$ & Fold 1 & Fold 2 & Fold 3 & Fold 4 & Fold 5 & Rata-Rata \\
\hline All & $86,25 \%$ & $87,25 \%$ & $86,25 \%$ & $91,25 \%$ & $95,5 \%$ & $88,75 \%$ \\
\hline 1 & $73,75 \%$ & $83,75 \%$ & $78,75 \%$ & $83,75 \%$ & $86,25 \%$ & $81,25 \%$ \\
\hline 2 & $78,75 \%$ & $93,75 \%$ & $92,5 \%$ & $91,25 \%$ & $87,5 \%$ & $88,75 \%$ \\
\hline 3 & $81,25 \%$ & $91,25 \%$ & $90 \%$ & $91,25 \%$ & $92,5 \%$ & $89,25 \%$ \\
\hline 4 & $82,5 \%$ & $90 \%$ & $90 \%$ & $91,25 \%$ & $93,75 \%$ & $89,5 \%$ \\
\hline 5 & $82,5 \%$ & $88,75 \%$ & $88,75 \%$ & $92,5 \%$ & $93,75 \%$ & $89,25 \%$ \\
\hline
\end{tabular}

Ket :

1) Fold 1 : Citra 1 dan 2 sebagai data uji dan citra $3,4,5,6,7,8,9,10$ sebagai data latih.

2) Fold 2 : Citra 3 dan 4 sebagai data uji dan citra 1,2,5,6,7,8,9,10 sebagai data latih.

3) Fold 3 : Citra 5 dan 6 sebagai data uji dan citra 1,2,3,4,7,8,9,10 sebagai data latih.

4) Fold 4 : Citra 7 dan 8 sebagai data uji dan citra $1,2,3,4,5,6,19,10$ sebagai data latih.

5) Fold 5 : Citra 9 dan 10 sebagai data uji dan citra $1,2,3,4,5,6,7,8$ sebagai data latih 
Dengan menggunakan metode fold cross validation, akurasi rata-rata tertinggi bernilai $89,25 \%$ dengan penggunaan nilai eigen 3 dan 5 lebih tinggi dibandingkan semua nilai eigen didapat akurasi $88,75 \%$.

\subsection{Metode Kernel Fisher's Discriminant Analysis}

Penelitian oleh Setyawan,I [11]mencoba sistem face recognition ini menggunakan database dengan 30 model wajah dengan 105 variasi pose, aksesoris wajah dan ekspresi wajah. Semua gambar yang digunakan menggunakan background putih. Sehingga, total sampel yang dimiliki adalah 3150. Setiap sampel memeiliki dimensi 4096 (setiap gambar berukuran 64 x 64 pixels). Pada gambar 3 merupakan beberapa contoh sampel database.

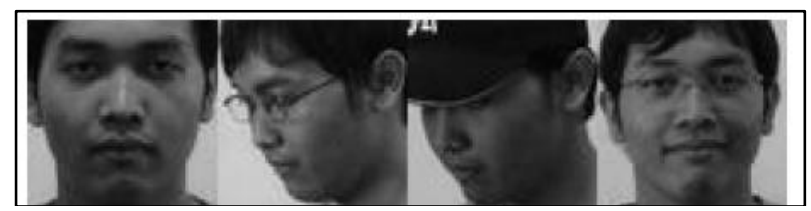

Gambar 3. Contoh database sampel[11]

Telah disebutkan pada bagian 2 bahwa pengujian atau perhitungan keberhasilan dari sistem face recognition ini menggunakan metode cross validation.

Hal pertama yang harus dilakukan ketika menggunakan metode cross validation ini yaitu harus menentukan kelas. Pada percobaan ini kelas dibagi menjadi 2, yaitu suspect dan nonsuspect. Lalu proses data menggunakan 2-fold cross validation. Pisahkan data secara acak menjadi 2-fold yang setiap fold nya memiliki banyak data yang sama. 1 fold yang sudah diacak tadi disebut folds training subset, dan 1 fold yang lain disebut testing subset. Lalu kita masukkan setiap proyeksi dari testing subset dan training subset menggunakan KFDA dan mengklasifikasikan kelas nya menggunakan KNN. Proses ini bekerja 10 kali dengan tujuan menjalankan 10 kali metode 2-fold cross validation. Sebelum menjalankan sistem ini, harus menentukan parameter yang digunakan dan parameter tersebut adalah panjang vektor $(n)$, kernel $(\sigma)$, dan banyak nya neighbor $(k)$. Besar parameter yang digunakan pada sistem face recognition ini adalah $n=100, \sigma=1000$, dan $k=3$.

Dan hasil pengujian pada percobaan ini dengan menjalankan sistem 10 kali dengan metode 2 -folds cross validation, didapat rata rata keberhasilan sebesar 83,10 \%.

Dapat disimpulkan juga bahwa hasil percobaan ini bergantung pada parameter - parameter yang kita atur sebelumnya. Dengan mengubah nilai parameter, besar kemungkinan dapat mengimprovisasi keberhasilan kinerja sistem.

Pada penelitian terdahulu yang didapat dengan penggunaan metode Two Dimensial Principal Component Analysis (2DPCA) dan Kernel Fisher's Discriminant Analysis mengenai hasil dari penelitian terdapat perbedaan dan kesamaan. Perbedaan terdapat pada citra wajah yang dijadikan sebagai data. Pada penelitian E.B.Utomo [1], menggunaan citra wajah yang berkerudung sebagai data yang akan diproses oleh sistem, sedangkan pada penelitian I.Setiawan Et all [11], menggunakan citra wajah pada umumnya. Adapun kesamaan dalam penelitian ini terdapat pada pengambilan citra wajah dengan parameter ekspresi yang berbeda-beda, metode klasifikasi yang digunakan dalam pengujian adalah $K$-Neirest Neighbor dan penggunaan metode dalam analisis hasil pengujian menggunakan $K$-Fold Cross Validation dengan jumlah 10 data. 
Analisa Metode Pengenalan Wajah Two Dimensial Principal Component Analysis (2DPCA) dan Kernel Fisher Discriminant Analysis Menggunakan Metode Klasifikasi KNN ( $K$-Nearest Neighbor)

Penelitian E.B.Utomo [1], menggunakan metode Two Dimensial Principal Component Analysis (2DPCA) dan pada penelitian I.Setiawan Et all [11] dengan metode Kernel Fisher's Discriminant Analysis kedua metode tersebut berfungsi untuk mengekstraksi citra wajah, dengan data yang akan dievaluasi hasil dari ekstraksi metode-metode tersebut disajikan pada jumlah 5 fold dan 2 fold, hasil evaluasi menggunakan metode $K$-Fold Cross Validation didapat tingkat akurasi tertinggi dari kedua metode tersebut yakni bernilai $89,25 \%$ dan $83,10 \%$. Jika kedua penetilian sama-sama menggunakan 2 fold, maka dihasilkan tingkat akursainya dengan nilai $88,73 \%$ dan $83,10 \%$. Dengan ini penggunaan metode Two Dimensial Principal Component Analysis (2DPCA) dinilai lebih akurat dalam pengenalan citra wajah jika dibandingkan dengan metode Kernel Fisher's Discriminant Analysis.

Perbandingan awal yang dapat dilihat dari kedua metode ini adalah asal mula pengembangan nya. Metode KFDA ini merupakan hasil pengembangan dari metode LDA, sedangkan metode 2DPCA merupakan hasil pengembangan dari metode PCA. Kedua metode ini memiliki fungsi yang sama yaitu sebagai metode ekstrasi ciri citra wajah yang ingin diketahui. Perbedaan dari kedua metode ini adalah metode KFDA menginput data dengan cara memetakan sample berdimensi rendah ke berdimensi tinggi. Sedangkan metode 2DPCA merubah gambar menjadi matriks vektor berdimensi tinggi guna untuk menghitung matriks kovarian nya, metode ini dapat memperbaiki evaluasi matriks kovarian yang ukurannya lebih besar menjadi lebih akurat dan dapat mempercepat perhitungan eigen vector menjadi lebih efisien. Serta pada inputan citranya, metode 2DPCA menggunakan 360 data uji wajah pada 40 orang dengan 10 citra wajah pada masing-masing yang menggunakan berbagai jenis kerudung, sedangkan pada metode KDFA, menggunakan 3150 data uji dengan 105 ekpresi wajah pada 30 orang. Dan didapat hasil pada metode Two Dimensial Principal Component Analysis (2DPCA) dengan 5 fold data didapat akurasi 89,25\%, dan pada metode Kernel Fisher's Discriminant Analysis dengan 2 fold didapat akurasi 83,10\%. Dengan perbandingan kedua metode menggunakan 2 fold data didapat nilai akurasi $88,73 \%$ dan 83,10\%.

\section{KESIMPULAN}

Dari analisis perbandingan penggunaan metode Two Dimensial Principal Component Analysis (2DPCA) dan Kernel Fisher's Discriminant Analysis pada sistem pengenalan wajah didapatkan beberapa kesimpulan, sebagai berikut :

1. Metode Two Dimensial Principal Component Analysis (2DPCA) merupakan penyempurnaan dari metode sebelumnya yakni Principal Component Analysis (PCA). Dan metode Kernel Fisher's Discriminant Analysis penyempurnaan dari metode sebelumnya yakni Linear Discriminant Analysis .

2. Algoritma $K$-Nearest Neighbor digunakan untuk klasifikasi citra wajah sedangkan metode $K$-Fold Cross Validation digunakan untuk menghimpun dan mengevaluasi hasil pengujian.

3. Metode Two Dimensial Principal Component Analysis (2DPCA) dengan 5 fold data didapat akurasi 89,25\%, dan pada metode Kernel Fisher's Discriminant Analysis dengan 2 fold didapat akurasi 83,10\%. Dengan perbandingan kedua metode menggunakan 2 fold data didapat nilai akurasi $88,73 \%$ dan 83,10\%. Penggunaan Metode Two Dimensial Principal Component Analysis (2DPCA) lebih akurat dibandingkan metode Kernel Fisher's Discriminant Analysis dalam pengenalan citra wajah. 


\section{REFERENSI}

[1] E. B. Utomo, "Pengenalan Wajah Wanita Berkerudung Menggunakan Metode 2DPCA dan K-Nearest Neighbor," pp. 1-7, 2014.

[2] Lina and A. J. Feriyansah, "Sistem Pengenalan Wajah Dengan Metode 2D-PCA," J. Pendidik. Teknol. Komun. Terap., no. July 2012, p. 138, 2012.

[3] R. T. Wahyuningrum and F. Damayanti, "Efficient kernel-based two-dimensional principal component analysis for smile stages recognition," Telkomnika, vol. 10, no. 1, pp. 113-118, 2012.

[4] J. Yang, D. Zhang, A. F. Frangi, and J. Y. Yang, "Two-Dimensional PCA: A New Approach to Appearance-Based Face Representation and Recognition," IEEE Trans. Pattern Anal. Mach. Intell., vol. 26, no. 1, pp. 131-137, 2004.

[5] L. Sirovich and M. Kirby, "Low-dimensional procedure for the characterization of human faces," J. Opt. Soc. Am. A, vol. 4, no. 3, p. 519, 1987.

[6] J. Shah, M. Sharif, M. Raza, and A. Azeem, "A Survey: Linear and Nonlinear PCA Based Face Recognition Techniques," Int. Arab J. Inf. Technol., no. November, 2013.

[7] K. Liu, Y. Q. Cheng, and J. Y. Yang, "Algebraic feature extraction for image recognition based on an optimal discriminant criterion," Pattern Recognit., vol. 26, no. 6, pp. 903-911, 1993.

[8] J. Yang and J. Y. Yang, "From image vector to matrix: A straightforward image projection technique-IMPCA vs. PCA," Pattern Recognit., vol. 35, no. 9, pp. 19971999, 2002.

[9] Informatikalogi, "Algoritma K-Nearest Neighbor (K-NN)," 2017. [Online]. Available: https://informatikalogi.com/algoritma-k-nn-k-nearest-neighbor/.

[10] V. S. Vijayalakshmi, B. Shwetha, and S. V Sathyanarayana, "Image Classifier based Digital Image Forensic Detection-A Review and Simulations," Int. Conf. Emerg. Res. Electron. Comput. Sci. Technol., 2015.

[11] I. Setyawan, A. F. Putra, I. K. Timotius, and A. A. Febrianto, "Face recognition using Kernel Fisher's Discriminant Analysis and nearest neighbor," Proc. 2011 6th Int. Conf. Telecommun. Syst. Serv. Appl. TSSA 2011, pp. 5-7, 2011. 